\title{
Basic Technologies and Equipment Used for Peat Deposits Development in Foreign Countries
}

\author{
Oleg Misnikov ${ }^{1, *}$ \\ ${ }^{1}$ Tver State Technical University, 170026 A. Nikitin Street 22, Tver, Russia
}

\begin{abstract}
The article discusses the perspectives of the use of peat to solve several issues. First, there are prospects of using peat fuel for solving energy problems. Second, there is a need to use peat processing products for increasing soil fertility and combating desertification of territories. The author considers a possible solution of the problem of utilization of livestock wastes together with the obtaining of peat composts. The objective prerequisites for increasing the volume of peat extraction in the Russian Federation are given. The article discusses features of the main technologies for the extraction of milled and sod peat. The interrelation of the technology of peat harvesting with the technology of its further processing is substantiated. A limited amount of technological equipment produced in Russia causes the need for its importing. The paper overviews the main peat extraction technologies used in Western Europe and Canada. An analysis of the features of technological processes related to the characteristics of raw materials and the needs of the market is made. The tendencies in development of production of technological equipment are considered. Currently, it is recommended to use mixed sets of technological equipment of various manufacturers.
\end{abstract}

\section{Introduction}

Since the middle of 1970s, the use of natural gas and liquid fuels began to exceed the consumption of solid fossil fuels such as coal, shales and peat in the fuel and energy balance of the Russian Federation. Currently, the share of peat use as fuel is about $0.05 \%$ [1]. Despite of all the advantages of natural gas, it is impractical to target all energy-consuming industries of Russia for this type of fuel. First of all, this is due to the constantly increasing volumes of exports and the growth of global prices for gas [1]. According to the forecasts of Russian and foreign experts [1-3], the role of different types of biofuel and, primarily, peat will increase. For example, already now peat is a cost-efficient local fuel in some regions of the Russian Federation, where it is used at a higher technological level. It can compete with the best brands of imported coal, mazut, and in some cases with natural gas.

It goes without saying that such high-quality resources as natural gas and oil are expedient for deep chemical processing, domestic consumption, and also for power generation. In these cases, the greatest technical and economic effect will be achieved [1]. Combustion of local types of fuels instead of long-range coal of better quality is cost-efficient due to lower

\footnotetext{
* Corresponding author: tma.geolog@kuzstu.ru
} 
transportation and transshipment costs. This is applicable when the shipment distance does not exceed 80-100 km for the milled and 100-150 km for sod peat.

There is a relatively small amount of humus in the soils of the Central Economic Region of the Russian Federation, unlike in chernozems. This is also relevant for many foreign countries, especially for the territories that have undergone desertification. Without the use of organic fertilizers, it is almost impossible to solve this problem. In the early 1990s, the demand of agricultural lands for organic fertilizers was only half satisfied in Russia. Presently, the situation has become even more aggravated. Agricultural enterprises of the country introduce on average approximately 1.1-1.3 tons of organic fertilizers per hectare of arable land. This is only $2.6-5.5 \%$ of the scientifically based standard (depending on soil properties). In many regions of the country there is a sharp decrease in the humus content in the soil, which is the main indicator of its fertility $[3,4]$.

Another serious problem in is the situation with the utilization of organic wastes from livestock farms. Previously (before 2000), peat was widely used to solve this problem. In 2012, the annual volume of waste from livestock and poultry farms in the form of liquid manure, poultry droppings and sewage was about 700 million $\mathrm{m}^{3}$ [3]. And only $30 \%$ of all the available volume of waste was used as fertilizers, and the rest of it constituted a real threat to the environment. It was found that the negative impact of liquid manure on environmental pollution is 10 times higher than the impact of municipal sewage [5]. According to the most conservative estimates, it is necessary to process more than 200 million tons of manure sewage with various levels of purification in the Russian Federation annually.

It is also difficult to find an acceptable alternative to peat to solve this problem. The preparation of peat-manure composts is an effective way of recycling waste with the simultaneous production of organic fertilizers. In order to do it efficiently it is also necessary to extract about 200 million tons of peat per year. This is also an important part of increasing soil fertility, since peat composts are qualitatively better in their agrochemical characteristics from "pure" peat.

Thus, currently, there are objective prerequisites for a drastic increase in the use of peat in the Russian Federation. Naturally, to meet the demand for peat products, it will be necessary to increase the volumes of harvesting of peat raw materials.

\section{Review}

The use of known technologies for the extraction of peat (Figure 1) will depend on the direction of its further processing. However, a sharp increase in production will be restrained due to the insufficient number of technological equipment available on the domestic market. At the moment, there is only one enterprise for the production of some technological equipment for peat extraction in the Russian Federation. The same applies to the machines used for the preparation and repair of production areas on peat deposits.

The complete sets of equipment, however, are produced by the following foreign companies: VAPO OY, SUOKONE OY, ECOFIELD OY, RAISELIFT OY (Finland); BORD na MONA, DIFCO (Ireland); PREMIER TECH (Canada), as well as a number of Belarusian enterprises.

The equipment produced by the Western manufacturers is primarily oriented to the methods of peat extraction that have become most widespread in these countries. Therefore, when designing domestic peat enterprises in the near future, we will have to focus on imported technological and peatland-preparation equipment. And it will not always fully correspond to the extraction technologies used in the country. 


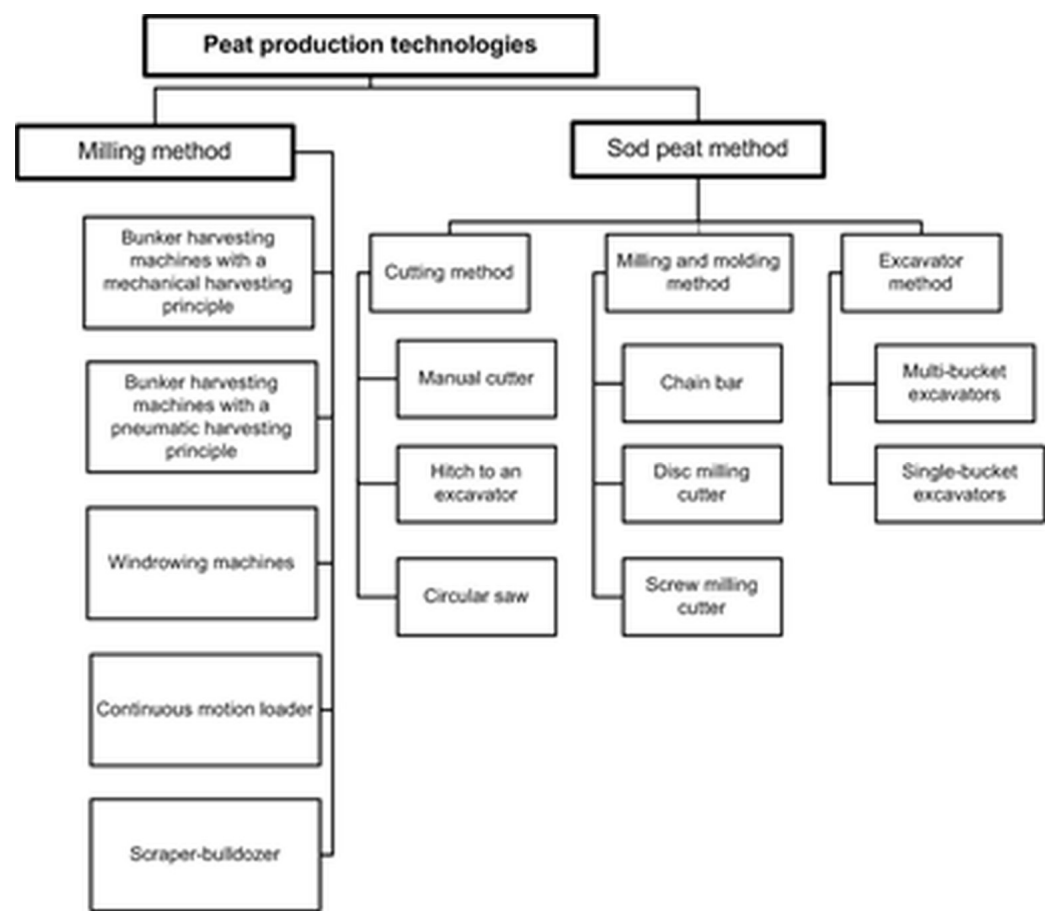

Fig. 1. Peat extraction technologies.

In the Finnish peat industry, the extraction of milled peat by separate harvesting method (HAKU), as well as by using mechanical and pneumatic trailed bunker harvesters [5]. The sod peat is also harvested by milling and molding method. [6]. Over the past 40 years, Finland has consistently increased the extraction and use of peat. Now it is one of the leading countries in the world in the production of fuel peat. In this northern country, with its difficult for peat production conditions, about 5-10 million tons of fuel peat is produced annually. Currently, peat is used in Finland mainly as a source of energy, and also as a raw material for obtaining agricultural products (crop production and partly livestock). Fuel peat accounts for about $90-93 \%$, while the agricultural one $-6-7 \%$. The share of milled peat for powergenerating industry is $90 \%$, and the rest part is sod peat. Except for the use on the domestic market peat for crop production it is also delivered to the markets of Central Europe.

More than $80 \%$ of milled peat is extracted by the method of separate harvesting. This method is the most effective for the use in the areas larger than 150-200 hectares. This technology and the equipment used in its application became widespread in the 1990s (here, Russian developments were used). Currently, various versions of this method are used. They differ from each other only by the models of used machines.

Bunker machines with mechanical and pneumatic harvesting principles produce about $20 \%$ of milled peat. In Finland, passive miller, active screw and knife milling machines are used for the milling during the production of fuel peat. Passive millers are used on various types of peat deposits for milling, as well as for the "lifting" of spread peat after precipitation. Screw mills are designed for sedge peat, and knife mills are designed for high density deposits.

Peat harrowing is one of the main operations that intensify the process of its field drying. During bad weather, the harrowing accelerates the drying process by $20-30 \%$. Depending on the weather conditions, from 2 to 3 harrows are conducted per cycle [7-9]. Wide-spread harrows with high production capacity are mainly used. The latest models utilize plastic working elements (blades) instead of the steel ones. This reduces the risk of peat ignition from sparks. Moreover, the plastic blades help to minimize the wetting of the spread by 
reducing the mechanical effect on a deposit. Peat swathing is usually carried out using a scraping ridger, hung in front of a tractor. The milling machine can be trailed behind the tractor. Milling of a new layer and harrowing are carried out simultaneously.

According to the HAKU method, the loading of peat from the swath into bunker trailers is carried out using a belt loader. As a rule, 4-6 trailers operate with one loader, they transport peat to the storage location - stacks. The capacity of trailers used for this method ranges from 28 to $45 \mathrm{~m}^{3}$. Nevertheless, loading and transportation is the costliest step in the process of producing milled peat. This stage accounts for about $30-40 \%$ of production costs.

Mechanical bunker harvesters are used for working on small and uneven deposits. After each cycle, from 1 to 4 swathes are formed on a strip (map) 20 meters wide. Each swath is gathered separately. Mechanical harvesters are effective on sites of about 50 hectares. The productivity of the harvesters is about $100 \mathrm{~m}^{3} / \mathrm{h}$. Mechanical harvesters load peat to an under-stack strip, or directly onto a stack (Figure 2), if the work site is small.

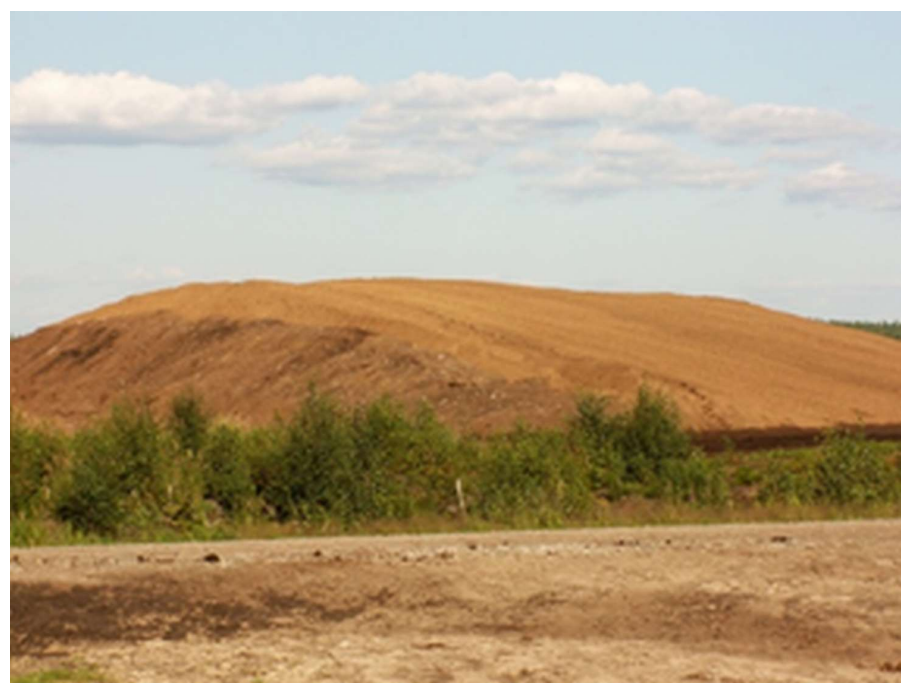

Fig. 2. A large storage unit (stack) of milled peat (VAPO OY company).

Pneumatic harvesters remove dry milled peat with suction nozzles. Pneumatic harvesters are ideal for small peatlands with a production area of about 35 hectares. The production cycle for pneumatic harvesting lasts one day. The harvesting machine sucks a mixture of air and peat through the nozzle into the cyclone. In a cyclone, peat is separated from air and accumulated in a hopper with a volume capacity of up to $40 \mathrm{~m}^{3}$. When the hopper is fully filled, the harvesting machine transports the peat to the stacks. Its productivity ranges from 50 to $80 \mathrm{~m}^{3} / \mathrm{h}$. The main drawback of this method is the release of dust from the fan outlet. Currently, there is a serial production of pneumatic harvesters, in which this shortcoming is minimized.

In Finland, stacks are formed using a bulldozer, which pushes peat to its top in layers. Another way of stacking is as follows: peat is brought to the top of the stack in a trailer. Peat unloading occurs on the move. In this case, the stack has the form of a steep slope (Figure 2). Stacking is completed with a bulldozer at the end of the production season. In this case, the goal is to create a compact, dense stack. This approach reduces its permeability to air. In noncompact stacks, there is a danger of self-heating and self-ignition [10]. The volume of stacks can reach 20 thousand $\mathrm{m}^{3}$.

The technology of sod peat extraction was developed in the USSR. It is used in Finland without fundamental changes. During sod peat production, excavation, processing, molding 
and spreading on the field are performed by a single milling and molding machine. It is aggregated with a powerful tractor. This operation accounts for about $50 \%$ of operating costs and is about one-fourth of the total cost of production. The permafrost layer (at the beginning of the extraction season) should not exceed $10 \%$ of the excavated layer, that is, in practice it does not exceed $5 \mathrm{~cm}$ [11]. Recently, the use of wave-shaped spreading has become widespread. It provides better drying conditions and, correspondingly, higher cycle gathering.

The harrowing of sod peat (for accelerating drying) is carried out with the help of spring rakes. It may be done up to two times per cycle. The first harrowing is carried out at a peat moisture content of $65 \%$. It must be done very carefully, making sure that the peat lumps below are not destroyed. In this case, the contact of the lumps with the moistened surface of the drying field is ruptured. The second harrowing is conducted at a peat moisture content of $55 \%$.

In Ireland, one of the most widespread methods of the production of milled peat is windrowing (Figure 3). Sod peat is extracted by excavating, milling and cutting methods. According to Russian experts, the windrowing method is the cheapest of all known (Figure 1). However, there are problems with its transportation from the production fields. In Finland, the transportation of peat is carried out by motor transport [12]. In Ireland, a narrow-gauge railroad is used, the same as at the peat production sites of the former Soviet Union. Milled peat in Ireland is used, mainly, for the needs of large energy industry and the production of fuel briquettes [13].

Ireland is an original country, which uses various methods of peat production: from the simplest - cutting to high-end production. Cut peat is produced by farmers, mainly for heating their homes. There are also options where one part of the technological operations is performed mechanically, and the other part is performed by using manual labor (practically, like in Russia until the 1940s). With this approach, the spreading of sod peat is performed with milling and molding machines or spreading machines. It means that, in fact, peat is bought at the molding stage when it is still on the field, and other operations related to its drying and gathering are performed manually. As a rule, they are performed by family members, as well as by hired workers. Peat fuel, obtained in this way, is of high quality, and its use allows to reduce heating costs (in comparison with liquid fuels) by 2.5-3 times. Moreover, this allows Irish producers of building rock formations to generate additional profits. It is formed by the selling peat, which is an overburden in many quarries (Figure 4) and is subject to disposal.

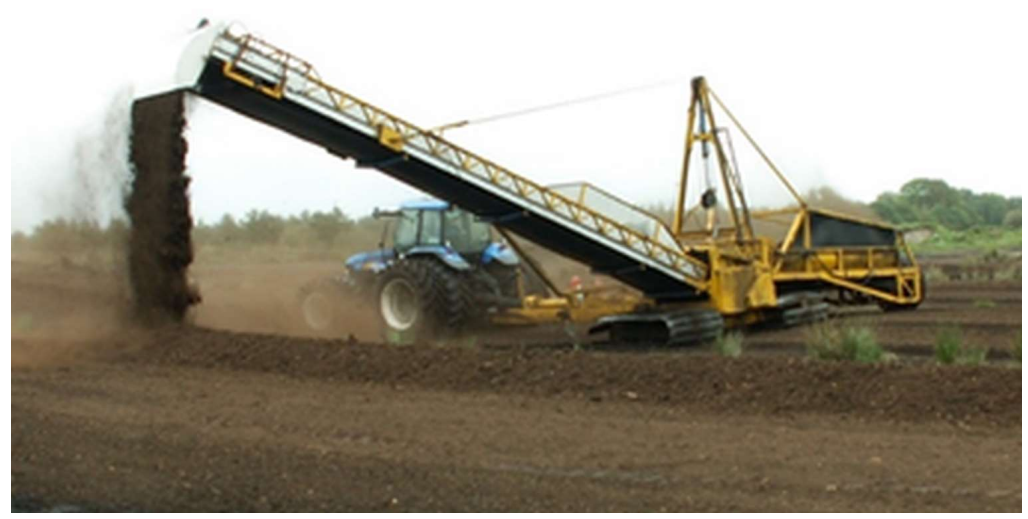

Fig. 3. Peat harvesting by windrowing machines (Bord na Mona, Ireland). 


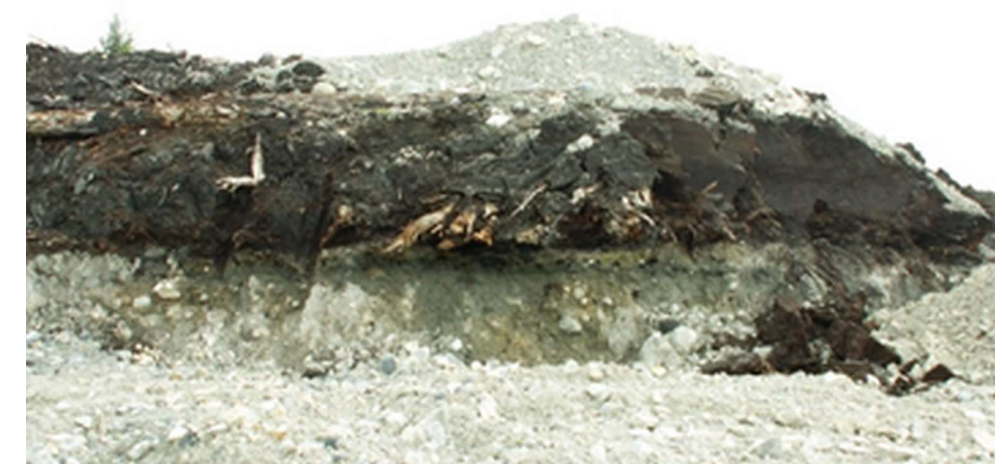

Fig. 4. The layer of peat above the extracted building rock.

The main producer of peat products in Ireland - "BORD na MONA". It produces, mainly, milled fuel peat and in a relatively small amount - sod peat with the excavating method. But this method differs from the one widely used in Russia. In the Russian Federation, multibucket excavators were used. Simultaneously with the extraction, they carried out mechanical processing [14] of the peat with a special press of the Rogov system. Ireland, in its turn, uses cheaper one-bucket excavators. A mechanical processing of peat before molding is done in the bunkers of spreading machines. They have three main differences from the machines used earlier in Russia (Figure 5):

- varying the tilt angle of a bead (to prevent the sticking of peat);

- a rotor with mixing blades (for preliminary averaging of excavated peat);

- a system of conveying (for the transportation and mechanical dispersion of peat) and pressure (for molding lumps) augers.

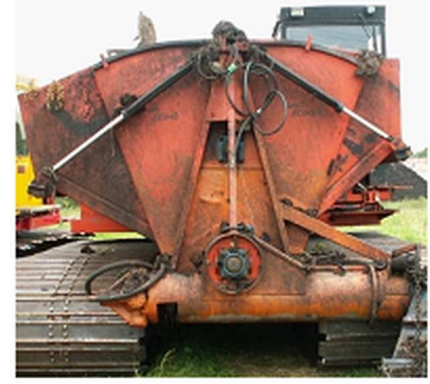

a)

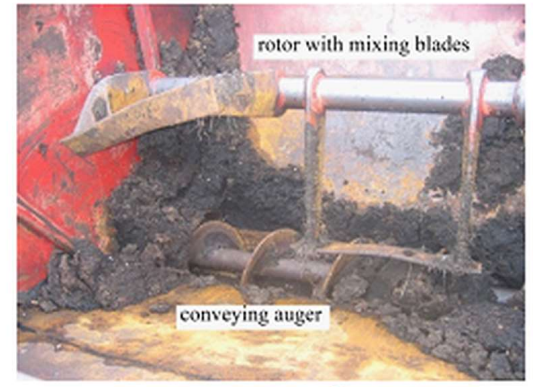

b)

Fig. 5. Technical devices used in the machine: varying of the tilt angle of a bead $(a)$, the mixing device and the processing screw $(b)$.

The scientific basis $[15,16]$ and experimental developments of such machines were carried out in the second half of the last century in the USSR. Industrial models were successfully tested at peat harvesting sites, but did not receive mass distribution. The analysis of Irish spreading machines ("DIFCO" and "BORD na MONA") indicates that many Russian engineering solutions are used here.

In Canada, the main used method is the extraction of peat by trailed (bunker capacity is $30 \mathrm{~m}^{3}$ ) and self-propelled (bunker capacity is $50 \mathrm{~m}^{3}$ ) pneumatic harvesting machines. Peat is unloaded from a self-propelled pneumatic harvester by a conveyor, and from a trailer it is unloaded by tilting the bunker. Canada also produces equipment for milling and harrowing 
peat, as well as some machines for the preparation and repair of production areas on peat deposits.

Belarusian manufacturers are still producing equipment using the documentation of the Soviet period. Some machines (for example, bunker harvesting machines) are modernized and in terms of their technical characteristics are quite competitive in comparison with the foreign analogues.

\section{Conclusion}

It should be noted that the general trend for all the peat equipment in Western Europe and Canada is the use of the wheel drive. Its application significantly reduces the weight of equipment and makes it possible to use tractors of lower power. In order to rapidly eliminate peat fires at their initial stage and prevent large fires, a number of technological equipment are additionally supplied with primary fire-extinguishing equipment. This is especially common in Finland. Such fire prevention measures in combination with organizational measures demonstrate good results. If in the past decades there have been major fires in peat deposits in Finland, at present they are practically reduced to zero.

Thus, when planning enterprises for the extraction and processing of peat raw materials, it is necessary to adapt technology to existing equipment. Moreover, in most cases it is necessary to work out options using mixed equipment sets [6], produced in different countries.

\section{References}

1. G. Alexandrov, A. Yablonev, E3S Web of Conferences, 21, 04011 (2017)

2. J. Lee, X. Yang, H. Song, Y. Ok, E. Kwon, Energy, 120, 929 (2017)

3. Panov V.V., Misnikov O.S., Gornyi Zhurnal, 7, 108 (2015)

4. Savel'eva A.V., N.V. Yudina, L.I. Inisheva, Solid Fuel Chemistry, 44(5), 305 (2010)

5. Schletterer M., Füreder L., Kuzovlev V.V., Beketov M.A., Ecological Indicators, 10(6), 1083 (2010)

6. Smirnov V.I., Misnikov O.S., Pukhova O.V., Gornyi Zhurnal, 7, 67 (2014)

7. E. Kremcheev, D. Nagornov, Life Science Journal, 11, 453 (2014)

8. E. Kremcheev, D. Kremcheeva, Research Journal of Pharmaceutical, Biological and Chemical Sciences, 7(3), 1284 (2016)

9. E. Kremcheev, D. Kremcheeva, Indian Journal of Science and Technology, 9(12), 89525 (2016)

10. Yudina N.V., Inisheva L.I., Solid Fuel Chemistry, 30(1), 12 (1996)

11. E. Kremcheev, A. Ivanov, Water and Ecology, 2, 48 (2016)

12. Zyuzin B.F., Misnikov O.S., Panov V.V., Kopenkina L.V. Gornyi Zhurnal, 5, 73 (2013)

13. N. Grevtsev, B. Aleksandrov, Gornyi Zhurnal, 3, 25 (2003)

14. E. Kremcheev, D. Nagornov, Ecology, Environment and Conservation, 23(2), 956 (2017)

15. A. Afanas'ev Colloid Journal of the Russian Academy of Sciences: Kolloidnyi Zhurnal, 53, 3, 425 (1991)

16. A. Afanas'ev, A. Boltushkin, Colloid Journal of the Russian Academy of Sciences: Kolloidnyi Zhurnal, 58, 2, 139 (1996) 